\title{
Pregnancy and heart disease: what Internists should know
}

\author{
Riccardo Gerloni, ${ }^{1}$ Domenico Panuccio ${ }^{2}$ \\ ${ }^{1}$ Urgency Medicine, Cattinara Hospital, Trieste; ${ }^{2}$ Internal Medicine, Bologna, Italy
}

\begin{abstract}
Pregnant women with heart disease are increasing due to medical and surgical progress and, nowadays, congenital heart disease is the most frequent heart disease affecting these women. Pregnancy represents a considerable effort for an altered heart with negative consequences for life quality, disease progression and mortality. Risk differs a lot among patients and depends not only on the type of heart disease. Clinician should stratify risk and offer patients a correct pre-counselling and accurate follow-up. At the same time Clinician should be able to diagnose rapidly heart failure as some cardiopathies, such as peripartum cardiomyopathy, are related to pregnancy and produce symptoms that can be confused with normal pregnancy progression. This brief review gives the opportunity to Internists to revise the most important aspects of management according to the recent literature. After having analyzed the pathophysiological mechanism of pregnancy, risk stratification and the salient elements of counselling, this review depicts the most important features of different heart diseases during pregnancy, giving warnings to Clinician about the fragile aspects to consider. Finally, it offers suggestions on therapy. General recommendations do not change during pregnancy, but some drugs are prohibited and dosage can sometimes be greater.
\end{abstract}

\section{Introduction}

Cardiac disease can rarely complicate pregnancy (e.g., only 1 to $4 \%$ of pregnancies in the United States), but it still remains a major cause of non-obstetric maternal morbidity and mortality. ${ }^{1}$

During pregnancy, a woman can suffer from heart failure because of a pre-existing heart disease or a new onset cardiopathy pregnancy correlated. Approximately $2 \%$ of pregnancies involve cardiac disease, and in the current era, most maternal disease is due to congenital heart disease (CHD). ${ }^{2}$ Currently cardiac surgery improvement of the last 50 years has permitted an increased number of survivors. Instead, in the past, rheumatic heart disease was the leading cause of heart

Correspondence: Riccardo Gerloni, Urgency Medicine, Cattinara Hospital, Strada di Fiume 447, 34100 Trieste, Italy. Tel.: +39.0403994217 - Fax: +39.0403994060.

E-mail: riccardogerloni@libero.it

Key words: Pregnancy; heart disease; heart failure.

Conflict of interest: the authors declare no potential conflict of interest.

Received for publication: 24 November 2016.

Accepted for publication: 14 December 2016.

This work is licensed under a Creative Commons Attribution NonCommercial 4.0 License (CC BY-NC 4.0).

CCopyright R. Gerloni and D. Panuccio, 2017

Licensee PAGEPress, Italy

Italian Journal of Medicine 2017; 11:288-304

doi:10.4081/itjm.2017.815 failure in pregnancy. ${ }^{3,4}$ Further, with increasing maternal age, other etiologies of heart disease should not be ignored and, particularly, ischemic and hypertensive heart disease should be considered in an over forty pregnant women. ${ }^{5}$

\section{Physiology of normal pregnancy}

Important hemodynamic changes appear during pregnancy and are responsible for heart failure in pregnant women with pre-existing heart disease. These changes begin early in pregnancy, generally during the first eight weeks, reach their peak during the late second trimester, and then remain relatively constant until delivery. ${ }^{6}$ The plasma volume and red cell mass are the first major cardiocirculatory modification, actually they expand in the $8^{\text {th }}$ week and peak around $30^{\text {th }}$ week, with a net plasma volume gain of 1000-1600 mL, corresponding to $30-50 \%$ above baseline. ${ }^{7}$ A greater increase in intravascular volume compared to red cell mass results in the dilutional anemia of pregnancy. This aspect generally results at 30-34 weeks when plasma volume peaks in relation to red cell mass and is associated with sodium and water retention. Actually $1000 \mathrm{mEq}$ of sodium and 6 liters of water are retained and distributed among amniotic fluid, fetus and intra and extracellular spaces. ${ }^{8}$ Further cardiac output increases to satisfy increase fetal and maternal metabolic needs. It can be estimated 30-50\% above baseline levels during the entire pregnancy, but half of this change occurs by $8^{\text {th }}$ week. This relevant change is a consequence of blood volume augmentation, afterload reduction and maternal heart rate rise. ${ }^{9}$ Systemic 
vascular resistance is reduced due to the high flow, low resistance circuit in the utero-placental circulation. Vasodilation is probably due to decreased sensitivity to norepinephrine and angiotensin, increase in nitric oxide and prostacyclin production and reduction in aortic stiffness. All these hemodynamic changes appear during pregnancy and if the heart is normal, they do not lead to adverse effects on central venous pressure and pulmonary capillary wedge pressure. ${ }^{10}$

The major effort for cardiovascular system has to be paid on labor and delivery, when abrupt hemodynamic changes appear. Actually, each uterine contraction releases $500 \mathrm{~mL}$ of blood into maternal circulation, provoking cardiac output increase that can be estimated up to $80 \%$ above baseline at the time of normal vaginal delivery. After delivery, decompression of uterus and inferior vena cava provokes an augmentation of venous return, which is compensated by blood loss $(400 \mathrm{~mL}$ during normal vaginal delivery and $800-1000 \mathrm{~mL}$ with a Cesarean section). ${ }^{11}$ The greater obligatory blood loss and the bad consequence of anesthesia required for $\mathrm{Ce}$ sarean section make vaginal delivery the preferable delivery for cardiac patients.

\section{Predictors of maternal cardiovascular events}

Several predictors of maternal cardiovascular events have been published. The best known are the CAPREG study and the ZAHARA study., ${ }^{4} 12$ The first one (Table 1) has been validated in several studies and appears valuable to predict maternal risk, although overestimation can occur. ${ }^{12,13}$ The predictors from the ZAHARA study ${ }^{12}$ (Table 2) have not been validated yet in other studies. It should be noted that predictors and risk scores from the CARPREG and ZAHARA studies are highly population-dependent; for example, the CAPREG study included patients with congenital and acquired heart disease and the ZAHARA study included only patients with congenital heart disease. Important risk factors such as severe pulmonary hypertension and severely dilated aortas are not pointed out in either study, limiting the usefulness of this approach. Thus, these predictors only provide for a snapshot of what the anticipated cardiovascular risk might be.

The best and more reliable cardiovascular risk score is the modified World Health Organization (WHO) classification ${ }^{14}$ (Table 3), which provides for the most favorable risk estimation model. It focuses on the congenital cardiac lesions that represent the most challenging for pregnancy, labor and delivery. It stratifies the risk into 4 classes. ${ }^{14,15}$ Risk is extremely low in women belonging to class I and cardiology follow-up during pregnancy may be limited to one or two examinations. Class II includes low-moderate risk and follow-up every trimester is recommended. Women in class III are at high risk of complications, and frequent (monthly or bimonthly) cardiology and obstetric examinaiton during pregnancy is recommended. Women in class IV should be advised against pregnancy. In case they become pregnant, a discussion of termination should be undertaken, but if they refuse, monthly or bimonthly examination is needed.

Table 1. CARPREG risk score.

Prior cardiac event (heart failure, transient ischemic attack, stroke before pregnancy or arrhythmia)

Baseline NYHA functional class $>$ II or cyanosis

Left heart obstruction (mitral valve area $<2 \mathrm{~cm}^{2}$, aortic valve area $<1.5 \mathrm{~cm}^{2}$, peak LV outflow tract gradient $>30 \mathrm{mmHg}$ )

Impaired systemic ventricular systolic function (ejection fraction $<40 \%$ )

One point for each predictor $(0$ point $=5 \%, 1$ point $=27 \%,>1$ point $=>75 \%)$. LV, left ventricular; NYHA, New York Heart Association.

Table 2. ZAHARA risk score.

History of arrhythmia event

Baseline NYHA functional class $>$ II

Left heart obstruction (aortic valve peak gradient $>50 \mathrm{mmHg}$ )

Mechanical valve prosthesis

Moderate/severe systemic atrioventricular valve regurgitation

Moderate/severe sub-pulmonary atrioventricular valve regurgitation

Use of cardiac medication pre-pregnancy

Repaired or unrepaired cyanotic heart disease

NYHA, New York Heart Association. 


\section{Counselling}

The risk of pregnancy depends on the specific heart disease and clinical status of the patient. Individual counselling by experts is recommended. ${ }^{15}$ Women with a known heart disease, that are inclined to become pregnant, should undergone an accurate evaluation and risk assessment prior to pregnancy. Usual drugs should be reviewed so that those which are contraindicated in pregnancy can be stopped or changed to alternatives if possible. The follow-up plan should be discussed with the patient and in case with her partner. Women with significant heart disease should be managed jointly by an obstetrician and a cardiologist with experience in treating pregnant patients with heart disease from an early stage. Highrisk patients should be managed by an expert multidisciplinary team in a specialist center. ${ }^{15}$ All women with heart disease should be assessed at least once before pregnancy and during pregnancy, and hospital delivery should be advised.
The history, physical examination, echocardiogram, and electrocardiogram (ECG) form the foundation of cardiac evaluation in all patients.

The great majority of pregnant patients have a normal ECG. The heart is normally rotated towards left with a 15-20 left axis deviation. Common physiological alterations include transient ST segment and $\mathrm{T}$ wave changes, the presence of a $\mathrm{Q}$ wave and inverted $T$ waves in lead III, an attenuated Q wave in lead AVF, and inverted $\mathrm{T}$ waves in leads $\mathrm{V} 1, \mathrm{~V} 2$, and, occasionally, V3. ${ }^{15}$ ECG changes can be due to a gradual change in the position of the heart and may mimic left ventricular (LV) hypertrophy and other structural heart diseases, which should be considered. Holter monitoring should be performed in patients with known previous paroxysmal or persistent documented arrhythmia such as ventricular tachycardia, atrial fibrillation, or atrial flutter, or in patients complaining symptoms of palpitations.

Exercise testing is useful to assess objectively the

Table 3. World Health Organization risk score.

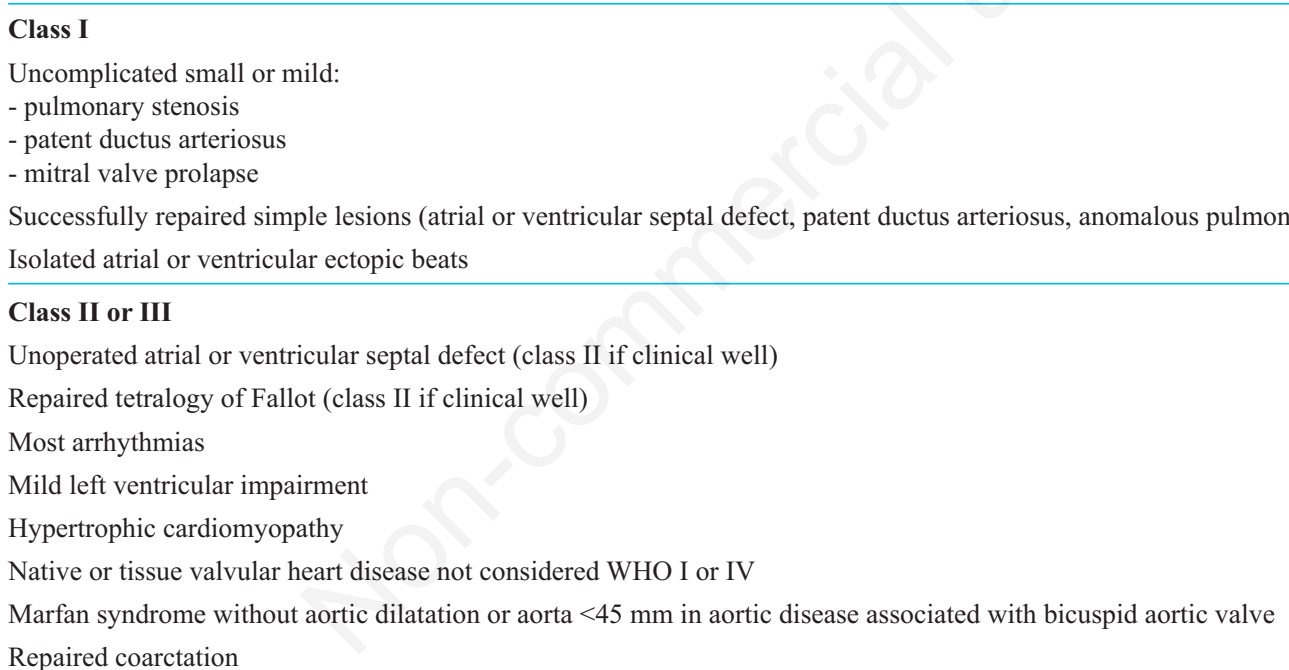

Class III

Mechanical valve

Systemic right ventricle

Fontan circulation

Cyanotic heart disease (unrepaired)

Other complex congenital heart disease

Aortic dilatation 40-45 mm in Marfan syndrome or aortic dilatation 45-50 $\mathrm{mm}$ in aortic disease associated with bicuspid aortic valve

Class IV

Pulmonary arterial hypertension of any cause

Severe systemic ventricular dysfunction (LVEF $<30 \%$, NYHA III-IV)

Previous peripartum cardiomyopathy with any residual impairment of left ventricular function

Severe mitral stenosis, severe symptomatic aortic stenosis

Marfan syndrome with aorta dilated $>45 \mathrm{~mm}$ or aortic dilatation $>50 \mathrm{~mm}$ in aortic disease associated with bicuspid aortic valve

Native severe coarctation

WHO, World Health Organization; LVEF, left ventricular ejection fraction; NYHA, New York Heart Association. 
functional capacity, chronotropic and blood pressure response, as well as exercise-induced arrhythmias. It is considered an essential test of the follow-up for grown up congenital heart disease patients and asymptomatic valvular heart disease ones. ${ }^{16,17}$ It should be performed in patients with known heart disease, preferably prior to pregnancy, to stratify risk. European Society of Cardiology (ESC) guidelines recommend performing submaximal exercise tests to reach $80 \%$ of predicted maximal heart rate in asymptomatic pregnant patients. ${ }^{15}$ There is no evidence that it increases the risk of spontaneous abortion..$^{18}$

Stress echocardiography using bicycle ergometry can be used to detect the presence and the extent of ischemia in high risk patients with suspected coronary artery disease. ${ }^{15}$ This exam can also be useful prior to conception to assess myocardial reserve in patients with prior peripartum cardiomyopathy (PC), which have recovered left ventricular ejection function (LVEF), valvular or CHD, another cardiomyopathy with borderline or mildly reduced LVEF.

Nuclear scintigraphy should be avoided during pregnancy because of radiation exposure.

\section{Ischemic heart disease}

Due to the increasing age of pregnant women, ignored atherosclerotic lesions become more and more frequent. Currently, diabetes and smoking are continuously increasing in the female gender considering last decades and hypercholesterolemia gets generally worse during pregnancy. For these reasons symptoms related to ischemic heart disease are more and more widespread during pregnancy. Two recent and detailed reviews focus on this problem. ${ }^{19,20}$

The incidence of myocardial infarct (MI) is very rare, about $0.6-1 / 10,000$, but it shows a bad prognosis with an estimated mortality between 5.1 and $37 \%$.

The vast majority of MI occurs in the third trimester, when cardiac oxygen demand increases for physiologic hemodynamic changes (increase in blood volume, systolic volume and heart beats) and typical anemia.

MI risk is higher in multiparas and augments with age $(8.8,19.0$ and 30.2 over 100,000 births respectively for women of 30-34, 35-39), over 40 years old.

It is quite difficult to diagnose MI in pregnant women, because they are relatively young, complain symptoms attributable to pregnancy, and show pseudo ischemic alterations of ECG without any pathological significance.

There is not enough literature on the best therapy of MI during pregnancy, but it should consider the effects on both the pregnant woman and the fetus. $\beta$ blockers and aspirin are generally well-tolerated, angiotensin converting enzyme (ACE) inhibitors and angiotensin receptor blockers (ARB) are discouraged for their embryonal toxicity. Other antiaggregants are not enough tested. Nifedipine is well-tolerated, other calcium-antagonists have not enough literature. Thrombolysis is dangerous because of its important hemorrhagic risk during pregnancy. Stent application is preferable, especially bare metal stent for its minor length of double antiaggregant therapy.

Pregnancy is not discouraged after MI or stent application, but it is advisable to evaluate accurately the woman, checking her ventricular function, the presence of residual ischemia or restenosis, and the electrical stability.

\section{Arrhythmias}

Arrhythmias cause the most frequent cardiologic symptom during pregnancy. They are generally due to atrial or ventricular premature beats (isolated or couplets, triplets, runs of non-sustained tachycardia). Sustained tachycardia is not more diffuse in pregnant woman.

Women who suffered from arrhythmia have an increased risk to face during pregnancy.

Multifactorial cause provoke arrhythmia during pregnancy: the presence of heart disease, augmented adrenergic activity due to hyper-estrogen production, atrial and ventricular stretching due to volume overload, typical hypokalemia, long QT interval for metabolic or pharmacologic causes.

Arrhythmogenic right ventricular cardiomyopathy (ARVC) is a heart disease with a fibro-adipose infiltration of both ventricles that provokes ventricular arrhythmias, heart failure and unexpected death. A recent article demonstrates that pregnancy does not influence cardiologic complication in women affected by ARVC. Actually $82 \%$ of 39 pregnancies in 26 women affected by ARVC did not manifest any major cardiac problems (heart failure or ventricular arrhythmia), 13\% showed ventricular arrhythmia and 5\% heart failure. All newborns were in good health conditions. ${ }^{21}$ However some women (20-44\%) complain of palpitations, syncope and vertigo, but there are scarce correlations with arrhythmia, about $10 \% .{ }^{22}$ For this reason it is recommendable to limit Holter ECG to those pregnant women who complain of daily palpitation, particularly if they suffer from a heart disease. Otherwise this examination seems to be useless.

Management of arrhythmia during pregnancy should be limited to do better. Causes of arrhythmia (electrolytic disturbances, thyroid disease, smoking, alcohol coffee or drug abuse) should be corrected. Antiarrhythmic therapy should be avoided during the first weeks and reserved to pregnant women with debilitating symptoms. Many drugs (digoxin, adenosine, flecainide, $\beta$-blockers) are used to treat arrhythmia 
during pregnancy, but data are not enough to have a reliable evaluation. ${ }^{23}$ Amiodarone should be avoided, because it causes hypothyroidism, prematurity and fetal growth retardation. Verapamil and diltiazem are quite secure. $\beta$-blockers are relatively secure, but prematurity and low weight newborns are reported. ${ }^{24}$

\section{Valvular heart disease}

\section{Mitral stenosis}

It represents the first cause of mortality for rheumatic heart disease during pregnancy. Moderate and severe mitral stenosis are generally symptomatic during pregnancy and an exercise testing can reveal symptoms at the beginning in an apparently asymptomatic woman. ${ }^{15}$ Mortality is up to $3 \% .{ }^{25}$ Prematurity rates are $20-30 \%$, intrauterine growth retardation $5-20 \%$, and stillbirth $1-3 \%{ }^{26}$ All patients with moderate or severe mitral stenosis (even when asymptomatic) should be advised against pregnancy and interventional correction should be performed pre-pregnancy. ${ }^{27}$ Clinical and echocardiographic follow-up is suggested monthly or bimonthly depending on hemodynamic tolerance. In patients with mild mitral stenosis, evaluation can be performed every trimester and prior to delivery. ${ }^{15}$ Percutaneous mitral commissurotomy with abdominal lead shielding should be performed during pregnancy only in case of NYHA class III/IV and/or estimated systolic pulmonary arterial pressure reaching $50 \mathrm{mmHg}$ at echocardiography despite optimal medical treatment, in the absence of contraindications. ${ }^{27,28}$

\section{Mitral and aortic regurgitation}

Valves regurgitation is generally less worrying than stenosis, because the decreased vascular resistance reduces regurgitation volume. However severe regurgitation is not well tolerated and pre-counselling should include exercise testing to evaluate functional capacity. ${ }^{15}$ Left ventricular dimension and function are other two important parameters to stratify risk of pregnancy. ${ }^{27}$ Ascending aortic diameters should be measured in women with aortic regurgitation, especially in those with bicuspid valves. ${ }^{15}$

Heart failure is the major risk for women with severe regurgitation and symptoms or compromised LV function, while arrhythmias are prevalent in asymptomatic women with preserved LV function. ${ }^{29}$ No increased risk of obstetric complications has been reported, however patients with symptomatic regurgitation have an increased risk of offspring complications. ${ }^{4}$ Patients with severe regurgitation and symptoms or compromised LV function or LV dilatation should be treated surgically before pregnancy. ${ }^{27}$

Follow-up depends on patient clinical status and can be planned every trimester in mild/moderate re- gurgitation, more often in severe regurgitation. Follow-up plans need to be individualized according to clinical status and symptoms.

\section{Congenital heart disease}

The population of patients with CHD continues to grow at an impressive rate, because these persons are now surviving beyond childhood as a result of medical and surgical advances. Pregnancy in this population needs an expert multidisciplinary team, including cardiologist, anesthesiologist, high risk obstetric and the possibility of keeping in touch with a center expert on CHD ${ }^{30}$ A sensitive discussion should be performed focusing on the long-term outlook for the mother, and, in some cases, on the possibility of limited longevity. Further multidisciplinary team should inform the patients about risks of miscarriage and poor fetal growth. ${ }^{31}$ If pregnancy is not advisable, appropriate advice regarding contraception is mandatory. ${ }^{32,33}$

\section{Risk factors}

A series of risk factors for maternal or fetal complications has been identified. ${ }^{12,34-38}$ Pulmonary hypertension, cyanosis, New York Heart Association (NHYA) functional class and natriuretic peptide levels are the most documented.

Pulmonary hypertension represents the most serious and worrying condition, particularly Eisenmenger syndrome. ${ }^{39}$ These patients manifest difficulties in managing the circulatory changes of pregnancy and, particularly, during labor, delivery and the postpartum period. The majority of maternal deaths occurs during delivery or postpartum period. Eisenmenger patients poorly tolerate post-partum hemorrhage and systemic vascular changes. Actually, systemic vascular resistance drop worsens the right-to-left shunt, favoring intense cyanosis. Hypoxemia can be fatal and mortality for women with Eisenmenger syndrome reaches $50 \%{ }^{40}$ On the other hand an excessive resistance rise can dramatically reduce cardiac output, causing fatal syncope. Although new therapies have improved outcome, leading mortality from 38 to $25 \%$ in women with pulmonary hypertension, fatal events remain unacceptably high. ${ }^{41}$

Preterm delivery and fetal growth are other two aspects to consider and patients affected by Eisenmenger syndrome manifest these problems in at least $50 \%$ of cases, with only 15 to $25 \%$ of pregnancies progressing to term. Therefore, counselling should aim to avoid pregnancy in women with Eisenmenger due to the high maternal mortality, important fetal risk and considerable thromboembolic complications. In case pregnancy occurs and termination is refused, heparin can be considered after 20 weeks. 
Cyanosis is one of the most important risk factors, because it can predict considerably fetal and maternal outcomes as it is evident from literature. ${ }^{35,36,42,43}$ Actually Whittemore et al..$^{34}$ demonstrated in a group of 44 pregnant women with cyanotic congenital heart disease that only $43 \%$ of the 96 pregnancies considered succeeded in live birth, 15 of which were even premature. Further, Shime et al. ${ }^{35}$ showed that $90 \%$ of pregnant women with cyanotic lesions have relevant postpartum complications, contrary to women with acyanotic lesions, of which only $19 \%$ develop complications.

Cyanotic congenital heart disease leads to erythrocytosis that can provoke symptoms of hyperviscosity such as headache, loss of concentration, fatigue and myalgias. Phlebotomy is indicated only in case of hematocrits over $65 \%$ and symptoms.

NHYA functional classification and natriuretic peptide levels are two other risk factors correlated to maternal deaths. The first one remains an important predictor of mortality even in pregnant women affected by congenital heart disease as it is evident from literature. ${ }^{36,44,45} \mathrm{McFaul}^{44}$ demonstrated in a group of 405 pregnant women with heart disease (of whom $31 \%$ had congenital heart disease) that the three maternal deaths occurred in women who were in NYHA class III or IV.

$\mathrm{N}$-terminal pro-B-type natriuretic peptide (NTproBNP) is considered an independent risk factor for cardiovascular events during pregnancy at 20 weeks of gestation ${ }^{45}$ and ZAHARA II $^{46}$ prospective multicenter observational study corroborates this affirmation, analyzing 213 pregnancies in 203 women with CHD. Actually, from this paper NT-proBNP $>128 \mathrm{pg} / \mathrm{mL}$ at $20^{\text {th }}$ week emerged as an independent predictor of adverse events, the negative predictive value of NTproBNP $<128 \mathrm{pg} / \mathrm{mL}$ resulted to be $96.9 \%$ and the positive predictive value of NT-proBNP $>128 \mathrm{pg} / \mathrm{mL}$ was $18.3 \%$.

Scientific demonstrations of the utility of B-type natriuretic peptide (BNP) for risk stratification of pregnant women with $\mathrm{CHD}$ are lacking. It is known that median plasma BNP in healthy pregnant women is normally twofold than in non-pregnant controls. ${ }^{47}$ Tanous et al. demonstrated that a small group of 66 pregnant women with congenital and acquired heart disease revealed a median BNP level over twofold than that found in the control group of 12 healthy pregnant women. ${ }^{48}$ Although this work is based on few patients and does not consider only patients affected by $\mathrm{CHD}$, it permits to hypothesize that BNP strongly correlates with adverse cardiac events in CHD patients. Actually, in this work all the women who manifested an adverse cardiac outcome (defined as arrhythmia requiring treatment, stroke, cardiac arrest or cardiac death, pulmonary edema, decline of NHYA functional class by at least two classes, or need for ur- gent invasive cardiac procedures during pregnancy or within six months after delivery) had an elevated BNP $(>100 \mathrm{pg} / \mathrm{mL})$. Further, one-third of women with an elevated BNP had an adverse cardiac event.

\section{Counselling}

Considering women with CHD, exercise testing is particular useful, because many patients have a sedentary life and can think erroneously to be asymptomatic.

Genetic counselling should be performed with the patient and her partner, analyzing a detailed family history. In case of CHD arising the novo, the possibility of having a baby affected by CHD is around $3-4 \%$. This percentage augments up to $10 \%$ if more than one sibling is ill..$^{49}$ Bicuspid aortic valve and left sided outflow tract obstructive lesions have the highest risk of recurrence. Some forms of CHD such as cono-truncal abnormalities (truncus arteriosus, pulmonary atresia and tetralogy of Fallot) are associated with 22q11.2 deletion and inherited as autosomal dominant lesion. A test can identify carriers of this chromosomal abnormality. Even Marfan or Nooan syndrome can be genetically tested.

Fetal echocardiography should be recommended at approximately 20 weeks of gestation. ${ }^{31}$

\section{Aortic stenosis}

Congenital aortic stenosis is common and represents $1-2 \%$ of the general population and it is generally due to bicuspid aortic valve. Most women are asymptomatic and for this reason exercise testing should be performed to evaluate functional capacity assessment. In case of symptoms or impaired left ventricular function, women should be recommended to avoid pregnancy and valvuloplasty or valvular replacement should be considered. ${ }^{30}$

Congenital aortic stenosis is frequently associated with aortopathy so that a detailed imaging of the ascending aorta should be performed before pregnancy. Women with an aorta greater than $4.5 \mathrm{~cm}$ should be recommended to avoid pregnancy until correction. ${ }^{2,50}$

In case a woman with severe aortic stenosis decides not to terminate pregnancy, heart failure and angina are two typical complications because of afterload drop, causing aortic gradient deterioration. Further, the reduced cardiac output leads to fetal complications such as intrauterine growth retardation, preterm birth, low birth weight, fetal death. ${ }^{51}$

Percutaneous aortic valvuloplasty has been performed in expert centers with lead shielding of the fetus in case valve is not calcific and only minimal aortic regurgitation coexists. Valve replacement remains the only possibility for patients with calcific valve and refractor to medical therapy. ${ }^{52}$ 


\section{Coarctation of the aorta}

This disease provokes impaired flow to the uterus with possible consequent fetal growth retardation and hypertension, which can facilitate aortic dissection. Actually, hormonal changes of pregnancy soften the aorta, making it more vulnerable to dilatation and dissection. However, hypertension should be corrected cautiously, because aggressive control may damage the fetus. It is rarely necessary to treat coarctation during pregnancy, when balloon and stent placement can more easily dissect aorta due to its fragility. ${ }^{31}$

\section{Tetralogy of Fallot}

Patients that have been corrected, without ventricular dysfunction, prior arrhythmias or clinical heart failure, tolerate pregnancy very well. However, they should be followed by a center with experience in CHD. ${ }^{19}$ Patients uncorrected should be counselled to be treated before pregnancy. Cardiac complications, such as arrhythmias and heart failure (the most frequent), thromboembolism, progressive aortic root dilatation, and endocarditis are pointed out in up to $12 \%$ of patients. ${ }^{30}$ Right ventricle dysfunction and/or moderate to severe pulmonary regurgitation are risk factors for cardiovascular complications. History of ablation and cardiothoracic ratio on chest radiography are predictors of adverse events..$^{53}$

Pregnant women with tetralogy of Fallot have an increased risk of fetal loss and congenital abnormalities so that fetal imaging should be performed. ${ }^{54}$

Follow-up depends on clinical status and on the presence of severe pulmonary regurgitation. It can be performed every trimester in the majority of women or monthly in the patients at highest risk. ${ }^{15}$

\section{Marfan syndrome}

It is an autosomal-dominant diagnosis with a fibrillin-1 mutation with a frequent cardiac involvement $(80 \%) .{ }^{30}$ Preconception counselling represents an important moment to depict modality of transmission, maternal and fetal risk and outcomes.

Aortic events remain the first cause of death and aortic dissection typically occurs in the last trimester or in post-partum. ${ }^{30}$ Aortic root $<4 \mathrm{~cm}$ has a low risk of aortic dissection (1\%). ${ }^{55}$ Even if there is not enough literature on this topic, pregnancy should be avoided in patients with an aortic root $>45 \mathrm{~mm} \cdot{ }^{15}$ If a patient presents an aortic diameter of 40-45 $\mathrm{mm}$, clinician should consider risk factors for dissection (family history of dissection, rapid growth) before giving advice about a possible pregnancy. ${ }^{56}$ Consideration of body surface area is important, especially in women of small stature. Following elective aortic root replacement, patients remain at risk for dissection in the residual aorta. ${ }^{57}$

\section{Interatrial and interventricular defects}

Interatrial defects are generally well tolerated during pregnancy. ${ }^{58}$ Interventricular defects present higher incidence of arrhythmias and heart failure.$^{58}$

Some (4-11\%) newborns of women with interventricular defects will be affected by the same disease. ${ }^{36}$

As endocarditis is rare, antibiotic prophylaxis is not advised.

\section{Other forms of congenital heart disease}

There are many other abnormalities belonging to CHD (Ebstein's anomaly, transposition of the great arteries, truncus arteriosus, pulmonary atresia) that we decide not to elucidate because of their rarity. An internist should know a general view of the most frequent forms of heart disease in pregnancy.

\section{Antibiotic prophylaxis in women with congenital heart disease}

Bacterial endocarditis is relatively rare during pregnancy in women with CHD. Literature is very scanty on this topic and contrasts are evident. Recommendation is made on expert opinions. Somebody is against prophylaxis, especially in interatrial defects, ${ }^{59}$ others suggest prophylaxis only for the patients at highest risk $^{60}$ (previous endocarditis, residual defects after surgery or first six months after surgery), others suggest prophylaxis for a larger number of patients. ${ }^{61}$ It is debatable if prophylaxis should be performed during delivery. A recent update concludes that it is not necessary neither for the highest risk patients, but it is advisable before dental or respiratory tract surgery. ${ }^{62}$

\section{Anesthesia and delivery}

In women with CHD induction of labor is generally safe and not associated with a higher incidence of Cesarean rates. Anesthesia and the delivery period is the most fragile period of the pregnancy and a multidisciplinary planning is often required. Vaginal delivery should be preferred unless there is an obstetric indication for Cesarean delivery. ${ }^{30}$ However, CHD patients at high risk, and who should have been counselled against pregnancy, can benefit from a Cesarean delivery. In order to limit maternal risk, the timing and delivery in a tertiary center are essential with a multi- 
disciplinary team, made up of experts in cardiology, maternal-fetal medicine, anesthesia and neonatology. A series of monitoring and procedures can be adopted to reduce maternal risks. ${ }^{30-31}$ For example maternal ECG monitoring should be performed to reveal any arrhythmia, intravenous line and/or central venous catheter should be placed to keep hemodynamic stabilization, continuous pulse oximetry should be used in cyanotic CHD to detect rapidly alterations of oxygen saturation, external defibrillator should be attached to the thorax of women with a history of poorly tolerated and/or life-threatening tachyarrhythmias, intra-arterial catheter can be adopted to monitor changes in blood pressure before induction of regional or general anesthesia in unstable patients or at high risk. The location and duration of postpartum monitoring should be evaluated individually, but in case of women in functional class III or IV, it should continue for at least $24 \mathrm{~h}$ in an intensive care unit. ${ }^{31}$

The preferred kind of anesthesia is epidural or lowdose combined spinal-epidural. ${ }^{63}$

\section{Other cardiac diseases}

\section{Hypertrophic cardiopathy}

There is no so much literature on pregnant women with hypertrophic cardiopathy (HC). Nonetheless Schinkel ${ }^{64}$ analyzed 9 cohorts, including 237 women and 408 pregnancies, demonstrating that events are rare. Actually, maternal mortality rate was $0.5 \%$ and $29 \%$ of patients complained worsening of symptoms or manifested some complications. Fetal mortality was similar to that of general population and was due to spontaneous abortion (15\%), therapeutic abortion $(5 \%)$, and stillbirth (2\%). Hence the diagnosis of $\mathrm{HC}$ does not preclude pregnancy, but patients affected should be evaluated before pregnancy to estimate maternal risk.

\section{Pathophysiology related to pregnancy in hypertrophic cardiopathy}

The increase in cardiac output in the first and second trimester is due to a larger stroke volume secondary to plasma volume increase. This physiological condition leads to enlargement of the ventricular cavity, which initially might reduce obstruction and gradient. ${ }^{65}$ However, proceeding pregnancy, volume overload neutralizes this effect and left ventricular outflow tract gradient increases, leading to left atrium distension with a higher risk of atrial fibrillation. During the third trimester, cardiac output generally increases because of heart rate augmentation. The changes of plasma volume and heart rate are not well tolerated in these patients and heart failure can manifest. ${ }^{65}$

During labor and delivery hemodynamic situation aggravates, because cardiac output increases further due to auto-transfusion from the contracting uterus and increased catecholamine levels. These changes lead to an additional increase in left ventricular outflow gradient and to a reduction in the diastolic filling period with a consequent risk of heart failure and pulmonary edema. ${ }^{65}$

\section{Risk assessment}

Even if pregnancy in $\mathrm{HC}$ is well tolerated, a subset of patients manifests complications. The most problematic group of patients is represented by the one with significant impairment of systolic function or with severe symptomatic obstruction. ${ }^{66}$ Women with a resting or provocable gradient $>50 \mathrm{mmHg}$ present higher risk and should be strictly followed by a multidisciplinary team. ${ }^{64}$ Patients with symptomatic advanced heart failure should be advised to terminate pregnancy because of an excess risk of mortality and morbidity. Obviously, surgery and alcohol septal ablation can eliminate obstruction and reduce maternal risk. For all these reasons assessment of pregnancy risk should consider clinical, echocardiographic and exercise testing evaluation, focusing attention on diastolic and systolic function, localization and severity of hypertrophy, outflow tracts gradients at rest and with provocation, cavity dimensions and gradients, mitral regurgitation severity and left atrial dimensions. ${ }^{66,67}$

Genetic counselling is appropriate before pregnancy and it should be focused on the possibility of genetic testing to confirm a disease-causing mutation, the risk of transmitting the genetic defect to the child, the variable disease penetrance, disease severity and prognosis. ${ }^{64}$

\section{Management}

Patients should be followed differently. WHO class II needs a clinical and echocardiographic examination every trimester, instead WHO class III warrants monthly or bimonthly control. ${ }^{66}$ During and after labor an increase in left ventricular outflow gradient can be caused by blood loss. ${ }^{64}$ Therefore hypovolemia should be promptly corrected with fluid administration or red cell transfusion if necessary. Cardiac arrhythmias may be dangerous, because they impair left ventricular filling and consequently outflow gradient. For this reason, all factors that can provoke arrhythmias such as hypovolemia, anemia, electrolyte disturbances should be avoided ${ }^{64}$ Electric cardioversion is considered to be safe for the baby and might be necessary in case of atrial fibrillation with hemodynamic impairment. ${ }^{68}$ Anesthesia and in particular epidural anesthesia, leading to vasodilatation can worsen left ventricular outflow gradient and produce hemodynamic instability. 


\section{Dilated cardiomyopathy}

It is characterized by left ventricular dilatation and dysfunction. It is generally known before pregnancy so that it can be easily differentiated from PC. It has generally a family history and can rapidly deteriorate during pregnancy due to hemodynamic load. ${ }^{15,69}$ Women with dilated cardiomyopathy should be advised about maternal risk, especially when LVEF is $<40 \%$ and should be suggested to terminate if LVEF is under $20 \%$. In case of mother's refuse, it is necessary for her to be followed up by a tertiary center with a multidisciplinary team. ${ }^{15}$

\section{Peripartum cardiomyopathy}

It is a potentially life-threatening disease that occurs in the peripartum period and provokes heart failure due to left ventricular dysfunction. However a precise definition does not exist and the ESC recently provided for a definition of $\mathrm{PC}$ as cardiomyopathy characterized by a reduced LVEF, generally $<45 \%$, evolving at the end of pregnancy or during the months after delivery, affecting women without previous known structural heart disease. ${ }^{70}$ Therefore it is not easy to distinguish dilated cardiomyopathy from PC in a pregnant woman and a study of 23 patients with dilated cardiomyopathy presenting before the last month of pregnancy demonstrated that these patients were clinically indistinguishable from patients with classically defined PC. ${ }^{71}$ A clear family history can suggest dilated cardiomyopathy, but clinical situations are generally not so simple.

\section{Epidemiology}

PC is relatively uncommon, but its incidence is increasing, because of more awareness and ability of diagnosing, rising maternal age and multifetal pregnancy, changing demographics. ${ }^{72}$ Actually, multiparity and multiple childbirths, family history, ethnicity, smoking, diabetes, hypertension, pre-eclampsia are all factors associated with PC. ${ }^{73}>50 \%$ of cases occur in women $>30$ years of age, ${ }^{72,74,75}$ with an odds ratio of 10 in comparison with women $>40$ and $<20$ years of age. ${ }^{76}$ The incidence is notably higher in black women and Gentry et al. ${ }^{77}$ demonstrated a 16-fold higher incidence of PC in black women compared to white ones. Further black women start suffering from $\mathrm{PC}$ in a younger age with a higher prevalence of hypertension and a lower rate of LVEF recovery. ${ }^{78} \mathrm{~A}$ recent meta-analysis considering 979 cases of PC, found a high prevalence of preeclampsia (22\%), which is $>4$ times the 3-5\% prevalence reported in general population. ${ }^{79}$ However, these two conditions are pathophysiologically different and PC is not simply the consequence of severe preeclampsia. Substance abuse, anemia, asthma, prolonged tocolysis, diabetes mellitus, obesity and malnutrition are other conditions associated with PC, but in these cases the association is not so well supported. ${ }^{80}$

The incidence of PC in the United States is reported from 1 in 1000 to 4000 live births..$^{72,74,76}$ However there are some places where incidence is particularly high: in Haiti, an incidence of 1 to 300 livebirths is reported ${ }^{81}$ and this difference could be due to racial background, nutritional deficiencies or high prevalence of eclampsia. In northern Nigeria, the incidence reaches 1 in 100 live births. ${ }^{82}$

\section{Pathophysiology}

Many hypotheses have been advanced, but it still remains much uncertainty on pathophysiology of this heart disease. However, recent research suggests that $\mathrm{PC}$ is a vascular disease, triggered by late-gestational secretion of potent anti-angiogenic agents from the placenta and the pituitary. ${ }^{83}$ This hypothesis has been already introduced in the past, but experimental demonstration supporting it, has been offered only recently. In particular a systemic angiogenic imbalance ${ }^{84}$ has been demonstrated on mice lacking cardiac PGC$1 \mathrm{alfa}$, a regulator of pro-angiogenic factors such as vascular endothelial growth factor (VEGF). These mice developed PC, which was responsive to dual proangiogenic therapy ${ }^{79,85,86}$ (VEGF plus bromocriptine). Further this hypothesis clarifies the reason why preeclampsia and multiple gestations are considered risk factors for PC. Actually, placenta normally secretes soluble fms-like tyrosine kinase (sFLt1), a VEGF inhibitor. In case of preeclampsia sFLt1 is higher and correlates with cardiac dysfunction. ${ }^{84}$

Another study that supports angiogenic imbalance is the one of Hilfiker-Kleiner et al. These authors demonstrated that mice with a knockout in the cardiac tissue-specific signal transduction and activator of transcription 3 (STAT3) develop PC ${ }^{87}$ Lack of STAT3 produces an increased cleavage of prolactin into an antiangiogenic and proapoptotic $16 \mathrm{kDa}$ isoform by cathepsin $\mathrm{D}$. This prolactin fragment is also responsible for endothelial damage and myocardial dysfunction. ${ }^{88}$ Reduced cardiac STAT3 levels have also been noted in terminally failing hearts from PC patients, ${ }^{87}$ but this is a nonspecific finding as it has also been found in end-stage dilated cardiomyopathy. ${ }^{89}$ Bromocriptine, an inhibitor of prolactin secretion, prevents the development of PC in mice. This drug was tested also on humans and two studies demonstrated positive results, but quality of these studies was very poor: few enrolled patients, not blinded trial, significant selection bias. ${ }^{90,91}$

Another pathophysiological hypothesis is based on hemodynamic stress, actually blood volume increase 
could cause a remodeling response of the heart with decrease in left ventricular systolic function. ${ }^{80}$

Another hypothesis is based on abnormal immune response. A fetal cell, arriving in the cardiac tissue can stimulate a pathological maternal immunological response. ${ }^{92,93}$ Supporting this hypothesis there are high titers of autoantibodies against normal human cardiac tissue proteins (including myosin), adenine nucleotide translocator, and branched-chain alpha-keto acid dehydrogenase ${ }^{94}$ that have been described only in patients affected and not in controls. Instead there are conflicting results on immunoglobulins which resulted higher than control in one study ${ }^{95}$ and identical to controls in another one. ${ }^{96}$

The last pathophysiological hypothesis considers myocarditis as a cause of $\mathrm{PC}$ and this hypothesis was stimulated by the frequent and variable finding of inflammatory infiltrates on right-sided heart endomyocardial biopsies. Specificity of this observation is poor and the role of myocarditis remains uncertain. ${ }^{97,98}$

\section{Clinical course and management}

The majority of PC is diagnosed in postpartum period, mostly in the week after delivery, and a small part presents during the second and the third trimester. ${ }^{71,99-}$ ${ }^{100}$ Although symptoms can be confused with those of normal pregnancy, signs of heart failure can easily be detected and echocardiography is mandatory to differentiate this cardiopathy from the others. It generally shows LV dilatation of variable degrees, LV systolic dysfunction, right ventricular and biatrial enlargement, mitral and tricuspid regurgitation and pulmonary hypertension. ${ }^{101,102}$ Recovery of LV systolic dysfunction is reported almost uniformly by 6 months, with little improvement of ejection fraction thereafter.

Data on ventricular arrhythmias are scarce and contradictory. ${ }^{103-108}$ Only $20 \%$ of women with PC receive an implantable cardioverter-defibrillator (ICD), because of important and persistent ventricular dysfunction. ICD should not be affixed early, because $50 \%$ of patients demonstrate recovery of ventricular function. Unfortunately, there are no parameters or indicators, which can point out patients unresponsive to therapy ${ }^{80}$

A multidisciplinary team of cardiologists and obstetricians should evaluate timing and mode of delivery. Mean birth weight, size and Apgar scores of neonates born to women with PC are generally lower, probably because of earlier gestational age at delivery. ${ }^{109}$

\section{Therapy}

Treating pregnant women with heart failure is not so different: general principles used are still valid in this setting, but it is important to avoid fetal risk de- termined by some drugs and procedures. ${ }^{15}$ Actually ACE inhibitors, ARBs, and aldosterone antagonists are teratogenic and should not be used during pregnancy, although their utilization is certainly useful in case of systolic heart failure ${ }^{109,110}$ In contrast, there is no scientific certainty on the treatment of diastolic heart failure, since data on the efficacy of specific agents are limited. ${ }^{109,110}$ All other advice that generally regulates treatment of heart failure is still valid in the context of pregnancy and in particular treatment of systemic factors, lifestyle modification, vaccinations (pneumococcal and annual influenza) and device therapy. If indicated, implantation procedures for cardiac resynchronization therapy and/or implantable cardioverter-defibrillator therapy should be performed preferably prior to or following pregnancy, because of radiation risk to the fetus. There is not so much literature on pregnant women with left ventricular assist devices. ${ }^{111}$ Concerns include maternal and fetal risks such as thromboembolism, necessity of anticoagulation and consequent risk of bleeding.

Each drug should be used cautiously and dosage can be sometimes increased because of alteration in the volume of distribution and glomerular filtration rate during pregnancy. ${ }^{112}$

\section{Angiotensin converting enzyme inhibitors and angiotensin receptor blockers}

ACE inhibitors and ARBs are contraindicated during pregnancy for their demonstrated adverse effects on the fetus during all trimesters of pregnancy, particularly the second and third trimester. Fetal renal failure and even neonatal death have been reported. ${ }^{113-115}$

If a woman with heart failure assuming ACE-inhibitors or ARBs plans a pregnancy, she should stop this therapy and evaluate possible consequences of this discontinuation in terms of clinical status, LV dilatation, or LVEF If the LVEF worsens, the risk of pregnancy should be reconsidered. If an ACE inhibitor or ARB is assumed during the first trimester, immediate discontinuation of the medication with subsequent monitoring, including fetal ultrasound, is recommended. ${ }^{15}$

ACE-inhibitors are present in low concentration in breast milk so that it cannot provoke adverse effects. ${ }^{116}$ No data exist on ARBs, therefore they should not be assumed.

\section{$\beta$-blockers}

These drugs are generally safe and useful during pregnancy, although an increased rate of fetal growth restriction is reported, ${ }^{117,118}$ particularly for atenolol. ${ }^{119}$ In practice $\beta-1$ selective (e.g., metoprolol) agents are preferable, since they probably interfere less with $\beta-2$ mediated uterine relaxation and peripheral vasodilation, 
but ultrasound scan follow-up is strictly recommended to evaluate fetal growth. Infants born to mothers treated with $\beta$-blockers should be observed for 72 to $96 \mathrm{~h}$ after delivery. $\beta$-blockers are generally present in low concentration in breast milk with the exception of atenolol. ${ }^{120}$ However metoprolol is the most advisable, because more recent drugs such as carvedilol and bisoprolol have not enough evidence in literature. ${ }^{116}$

\section{Digoxin}

Digoxin is considered to be safe in pregnancy, although some adverse effects are reported.121,122 Digoxin dose may need to be increased to achieve a therapeutic effect during pregnancy. The decision should be based upon the perceived adequacy of the therapeutic effect rather than serum levels only. ${ }^{123}$

Treatment of fetal tachyarrhythmias with digoxin is described and is due to its pharmacokinetic property. ${ }^{124}$

Digoxin concentration in breast milk is low so that no adverse effects have been described in breastfed newborns. ${ }^{116}$

\section{Hydralazine plus nitrate}

The combination of hydralazine plus nitrate (isosorbide dinitrate) is the recommended vasodilator therapy for pregnant women with heart failure, ${ }^{15,70}$ although this association has never demonstrated a strong evidence of usefulness as ACE inhibitor and ARBs. Actually hydralazine has been used for many years in the treatment of hypertension during pregnancy and appears to be safe for both the mother and fetus. ${ }^{125,126}$

Hydralazine can be assumed by nursing mothers due to its low level in breast milk. ${ }^{116}$ Evidence is lacking on the use of isosorbide dinitrate during breastfeeding. As ACE-inhibitor can be restarted in the postpartum period, it does not represent a relevant limit.

\section{Diuretics and aldosterone antagonists}

Diuretics are well tolerated during pregnancy. Intravenous administration is preferable for acute patients, while oral therapy is indicated for chronic ones.

The aldosterone antagonist spironolactone causes feminization of the male fetus in animal studies and there are no clinical data on humans, which can reject this experimental evidence. For this reason, spironolactone should not be used during pregnancy.

Few data support the use of spironolactone during breastfeeding, demonstrating that the level in breastmilk is low. ${ }^{116}$

\section{Intravenous therapy}

Intravenous nitroglycerin can be used in pregnant women with acute heart failure, particularly in case of high blood pressure treatment. ${ }^{127}$ Nitroprusside rather than nitroglycerin can be considered if remarkable and immediate afterload reduction is required. Examples of such settings include hypertensive emergency, acute aortic regurgitation, acute mitral regurgitation, aortic dissection, or acute ventricular septal defect. However, the dose and duration of therapy should be limited as much as possible because of the metabolism of this agent to thiocyanate and cyanide, which have determined fetal cyanide poisoning in animal models. ${ }^{128}$

If nitroprusside is necessary, breastmilk feeding should be interrupted because thiocyanate is excreted into breast milk. ${ }^{116}$

Intropes, such as dobutamine can be used in pregnant women if necessary for systolic dysfunction heart failure presenting with symptoms and signs of low cardiac output, unresponsive to medical therapy.

No information is available on the use of dopamine or dobutamine during breastfeeding. ${ }^{116}$ Intravenous dopamine infusion may decrease milk production but this has not been directly studied.

\section{Anticoagulants}

Venous thromboembolism is a rare complication of pregnancy as it occurs with an incidence of 1 in 500 up to 1 in 2000 pregnancies and it is more common postpartum than antepartum. ${ }^{129,130}$ It is due to the hypercoagulable state of pregnancy.

Indications for anticoagulation in women with heart failure during pregnancy is not different from standard general indications for anticoagulation. Given the possible thromboembolic risk in women with heart failure during pregnancy, some experts suggest anticoagulation in pregnant women with severe LV dysfunction. This approach is not supported by strong evidence and it is in contrast with recommendations for use of antithrombotic therapy in patients with heart failure generally. ${ }^{15,70}$

\section{Heparins}

As heparins do not cross the placenta, they represent the best way of anticoagulation during pregnancy. Low molecular weight heparins (LMWH) are the most used, because they are effective, demonstrate a more predictable effect and do not require activated partial thromboplastin time (aPTT) monitoring. ${ }^{131-135}$ However unfractionated heparins have still a role in case of renal failure, because LMWH are excreted only by kidneys, while unfractionated heparins have hepatic and renal excretion metabolism. Unfractionated heparin can also be administered intravenously to achieve a more constant level of anticoagulation or in case rapid discontinuation is advantageous (e.g., delivery, surgery). Fondaparinux is used although data 
are poor and not convincing. Their accepted indication is for patients who have had heparin-induced thrombocytopenia. ${ }^{136-138}$

Heparin dosage is higher during pregnancy because of weight gain and alteration of metabolism, plasma volume and renal clearance. ${ }^{139-146}$ For this reason prophylactic dose of LMWH in the first trimester of pregnancy is the same as that generally used in non-pregnant women (e.g., dalteparin 5000 units subcutaneously every $24 \mathrm{~h}$; enoxaparin $40 \mathrm{mg}$ subcutaneously every 24 h), but, after 20 weeks of gestation, it can be increased up to a maximum dose of enoxaparin $1 \mathrm{mg} / \mathrm{kg}$ once daily ${ }^{139}$ according to the thrombosis risk. Actually it has been demonstrated on a group of 57 women (82 pregnancies) at high risk of thrombosis that low-dose LMWH is not sufficient to avoid events. ${ }^{147}$ Basing on the same concept, unfractionated heparin is given subcutaneously every $12 \mathrm{~h}$, with increasing doses as the pregnancy progresses, from 5000 to 7500 units in the first trimester, from 7500 to 10,000 units in the second trimester, to 10,000 units in the third trimester. ${ }^{148,149}$ However some clinicians do not usually increase the dosage and limit prescription to 5000 units subcutaneously every $12 \mathrm{~h}$ throughout the pregnancy, but studies have concluded that this dose is probably not enough considering plasma heparin levels. ${ }^{145,150-153}$ As usual, there is no need of monitoring aPTT using prophylactic dose of unfractionated heparin.

Complications of heparin treatment should be faced as in non-pregnant women. Adequate assumption of calcium and vitamin D can avoid decrease in bone mineral density caused by long administration of heparin. Probably LMWH have the same effect on bone in comparison to unfractionated heparin. ${ }^{154,155}$

To limit bleeding risk, LMWH should be switched to unfractionated heparin at $36^{\text {th }}$ week of gestation and every treatment should be stopped when spontaneous labor begins or $24 \mathrm{~h}$ before planned induction of labor or Cesarean delivery, ${ }^{149}$ except in the highest risk setting (recent pulmonary embolus). Heparin can be reintroduced from 6 to $12 \mathrm{~h}$ after vaginal delivery or from 12 to $24 \mathrm{~h}$ after Cesarean delivery and treatment should be continued for at least six weeks at a prophylactic dosage in case of high risk of thrombosis.

\section{Warfarin and new oral anticoagulants}

Warfarin should be avoided, because it is teratogenic and produces fetal anticoagulation, causing embryopathy and fetal bleeding, including intracranial hemorrhage. Teratogenic effect is dose-correlated and doses inferior to $5 \mathrm{mg}$ /day seem to be safer, although teratogenic effect has been described also for these doses. ${ }^{156-158}$ The greatest risk of teratogenic effects is present when warfarin is assumed between $6^{\text {th }}$ and $12^{\text {th }}$ week of gestation, ${ }^{150}$ although toxicity is possible before or after this period. ${ }^{159-162}$ Typical abnormalities caused by warfarin assumption are chondromalacia punctata, with stippled epiphyses and nasal and limb hypoplasia ${ }^{150}$ and central nervous system abnormalities (e.g., optic atrophy, microcephaly, mental retardation, spasticity, and hypotonia)..$^{163-166}$

The risk of fetal hemorrhage seems to be greatest during and immediately after delivery, ${ }^{165-168}$ but it is reasonable to stop warfarin assumption after 34-36 weeks of gestation, substituting it with an another anticoagulant if appropriate. As fetal levels of coagulation factors do not correlate with maternal ones, infusion of fresh frozen plasma into the mother does not necessary reverse fetal anticoagulation.

Due to the high risk of thrombosis in women with mechanical heart valve, they can assume warfarin only in the second trimester of pregnancy when organogenesis has been mostly completed, but the risk of fetal bleeding is superior to other drugs. ${ }^{169-173}$

New oral anticoagulation cannot be assumed in pregnancy because we lack information about its safety. ${ }^{136,174}$

\section{References}

1. CEMACH. CEMACH Saving Mothers' Lives: reviewing maternal deaths to make motherhood safer - 20032005: the seventh report on confidential enquiries into maternal deaths in the United Kingdom. London: Centre for Maternal and Child Enquiries; 2008.

2. Warnes CA, Williams RG, Bashore TM, et al. ACC/AHA Guidelines for the management of adults with congenital Heart disease: A report of the American College of Cardiology/American Heart Association Task Force on Practice Guidelines. Circulation 2008; 118:2395.

3. Stangl V, Schad J, Gossing G, et al. Maternal heart disease and pregnancy outcome: a single-centre experience. Eur J Heart Fail 2008; 10:855.

4. Siu SC, Sermer M, Colman JM, et al. Prospective multicenter study of pregnancy outcomes in women with heart disease. Circulation 2001;104:515.

5. Rutherford JD. Heart failure in pregnancy. Curr Heart Fail Rep 2012;9:277.

6. Chapman AB, Abraham WT, Zamudio S, et al. Temporal relationships between hormonal and hemodynamic changes in early human pregnancy. Kidney Int 1998;54:2056.

7. Pritchard JA. Changes in the blood volume during pregnancy and delivery. Anesthesiology 1965;26:393.

8. Van Oppen AC, Stigter RH, Bruinse HW. Cardiac output in normal pregnancy: a critical review. Obstet Gynecol 1996;87:310.

9. Curran-Everett D, Morris KG Jr, Moore LG. Regional circulatory contributions to increased systemic vascular conductance of pregnancy. Am J Physiol 1991;261: H1842-7.

10. Geva T, Mauer MB, Striker L, et al. Effects of physiologic load of pregnancy on left ventricular contractility and remodeling. Am Heart J 1997;133:53. 
11. Fernandes SM, Arendt KW, Landzberg MJ, et al. Pregnant women with congenital heart disease: Anesthetic and obstetrical implications. Exp Rev Cardiovasc Ther 2010;8:439.

12. Drenthen W, Boersma E, Balci A, et al. Predictors of pregnancy complications in women with congenital heart disease. Eur Heart J 2010;31:2124.

13. Jastrow N, Meyer P, Khairy P, et al. Prediction of complications in pregnant women with cardiac diseases referred to a tertiary center. Int J Cardiol 2011;151:209.

14. Thorne S, MacGregor A, Nelson-Piercy C. Risks of contraception and pregnancy in heart disease. Heart 2006;92:1520.

15. ESC Guidelines on the management of cardiovascular diseases during pregnancy. Eur Heart J 2011;32:3147.

16. Baumgartner H, Bonhoeffer P, De Groot NM, et al. ESC Guidelines for the management of grown-up congenital heart disease (new version 2010). Eur Heart J 2010;31:2915.

17. Diller GP, Dimopoulos K, Okonko D, et al. Exercise intolerance in adult congenital heart disease: comparative severity, correlates, and prognostic implication. Circulation 2005;112:828.

18. Weisman IM, Zeballos RJ. Clinical exercise testing. Clin Chest Med 2002;32:273.

19. Kennedy BB, Baird SM. Acute myocardial infarction in pregnancy: an update. J Perinat Neonatal Nurs 2016;30:13.

20. Kealey AJ. Coronary artery disease and myocardial infarction in pregnancy: a review of epidemiology, diagnosis, and medical and surgical management. Can J Cardiol 2010;26:185.

21. Hodes AR, Tichnell C, te Riele ASJM, et al. Pregnancy course and outcomes in women with arrhythmogenic right ventricular cardiomyopathy. Heart. 2016;102:303.

22. Shotan A, Ostrzega E, Mehra A, et al. Incidence of arrhythmias in normal pregnancy and relation to palpitations, dizziness, and syncope. Am J Cardiol 1997; 79:1061.

23. Adamson DL, Nelson-Piercy C. Managing palpitations and arrhythmias during pregnancy. Heart 2007;93:1630.

24. Joglar JA, Page RL. Antiarrhythmic drugs in pregnancy. Curr Opin Cardiol 2001;16:40.

25. Hameed A, Karaalp IS, Tummala PP, et al. The effect of valvular heart disease on maternal and fetal outcome of pregnancy. J Am Coll Cardiol 2001;37:893.

26. Silversides CK, Colman JM, Sermer M, et al. Cardiac risk in pregnant women with rheumatic mitral stenosis. Am J Cardiol 2003;91:1382.

27. Vahanian A, Baumgartner H, Bax J, et al. Guidelines on the management of valvular heart disease: the Task Force on the Management of Valvular Heart Disease of the European Society of Cardiology. Eur Heart J 2007;28:230.

28. Elkayam U, Bitar F. Valvular heart disease and pregnancy part I: native valves. J Am Coll Cardiol 2005; 46:223.

29. Lesniak-Sobelga A, Tracz W, KostKiewicz M, et al. Clinical and echocardiographic assessment of pregnant women with valvular heart diseases - maternal and fetal outcome. Int J Cardiol 2004;94:15.

30. Bhatt AB, DeFaria Yeh D. Pregnancy and adult congenital heart disease. Cardiol Clin 2015;33:611.
31. Warnes CA. Pregnancy and delivery in woman with congenital heart disease. Circ J 2015;79:1416.

32. Silversides CK, Sermer M, Siu SC. Choosing the best contraceptive method for the adult with congenital heart disease. Curr Cardiol Rep 2009;11:298.

33. Thorne S, MacGregor A, Nelson-Piercy C. Risks of contraception and pregnancy in heart disease. Heart 2006;92:1520.

34. Whittemore R, Hobbins JC, Engle MA. Pregnancy and its outcome in women with and without surgical treatment of congenital heart disease. Am J Cardiol 1982;5 $0: 641$.

35. Shime J, Mocarski EJ, Hastings D, et al. Congenital heart disease in pregnancy: short- and long-term implications. Am J Obstet Gynecol 1987;156:313.

36. Siu SC, Sermer M, Harrison DA, et al. Risk and predictors for pregnancy-related complications in women with heart disease. Circulation 1997;96:2789.

37. Khairy P, Ouyang DW, Fernandes SM, et al. Pregnancy outcomes in women with congenital heart disease. Circulation 2006;113:517.

38. Siu S, Chitayat D, Webb G. Pregnancy in women with congenital heart defects: what are the risks? Heart 1999;81:225.

39. Child JS. Management of pregnancy and contraception in congenital heart disease. In: Perloff JK, Child JS, Aboulhosn J, eds. Congenital heart disease in adults, 3rd ed. Saunders/Elsevier; 2009.

40. Kahn ML. Eisenmenger's syndrome in pregnancy. N Engl J Med 1993;329:887.

41. Bédard E, Dimopoulos K, Gatzoulis MA. Has there been any progress made on pregnancy outcomes among women with pulmonary arterial hypertension? Eur Heart J 2009;30:256.

42. Presbitero P, Somerville J, Stone S, et al. Pregnancy in cyanotic congenital heart disease. Outcome of mother and fetus. Circulation 1994;89:2673.

43. Weiss BM, Atanassoff PG. Cyanotic congenital heart disease and pregnancy: natural selection, pulmonary hypertension, and anesthesia. J Clin Anesth 1993;5:332.

44. McFaul PB, Dornan JC, Lamki H, et al. Pregnancy complicated by maternal heart disease. A review of 519 women. Br J Obstet Gynaecol 1988;95:861.

45. Selzer A. Risks of pregnancy in women with cardiac disease. JAMA 1977;238:892.

46. Kampman MA, Balci A, van Veldhuisen DJ, et al. Nterminal pro-B-type natriuretic peptide predicts cardiovascular complications in pregnant women with congenital heart disease. Eur Heart J 2014;35:708.

47. Hameed AB, Chan K, Ghamsary M, et al. Longitudinal changes in the B-type natriuretic peptide levels in normal pregnancy and postpartum. Clin Cardiol 2009; 32:E60.

48. Tanous D, Siu SC, Mason J, et al. B-type natriuretic peptide in pregnant women with heart disease. J Am Coll Cardiol 2010;56:1247.

49. Nora A, Nora J, Optiz J, Reynolds J. Update on counseling the family with a first-degree relative with a congenital heart defect. Am J Med Genet 1988;29:137.

50. Hiratzka L, Bakris G, Beckman J et al. Guidelines for the diagnosis and management of patients with thoracic aortic disease. Circulation 2010;121:e266.

51. Silversides CK, Colman JM, Sermer M, et al. Early and 
intermediate term outcomes of pregnancy with congenital aortic stenosis. Am J Cardiol 2003;91:1386.

52. Bhargava B, Agarwal R, Yadav R, et al. Percutaneous balloon aortic valvuloplasty during pregnancy: Use of Inoue balloon and the physiologic antegrade approach. Cathet Cardiovasc Diagn 1998;45:422.

53. Veldtman GR, Connolly HM, Grogan M, et al. Outcomes of pregnancy in women with tetralogy of Fallot. J Am Coll Cardiol 2004;44:174.

54. Kamiya CA, Iwamiya T, Neki R et al. Outcome of pregnancy and effects on the right heart in women with repaired tetralogy of fallot. Circulation 2012;76:957.

55. Pyeritz RE. Maternal and fetal complications of pregnancy in the Marfan syndrome. Am J Med 1981; 71:784.

56. Meijboom LJ, Vos FE, Timmermans J, et al. Pregnancy and aortic root growth in the Marfan syndrome: a prospective study. Eur Heart J 2005;26:914.

57. Pacini L, Digne F, Boumendil A, et al. Maternal complication of pregnancy in Marfan syndrome. Int J Cardiol 2009;136:156.

58. Siu SG, Colman JM. Heart disease and pregnancy. Heart 2001;85:710.

59. Elkayam U. Pregnancy and cardiovascular disease. In: Zipes D, Libby P, Bonow R, Braunwald E, eds. Heart disease. A textbook of cardiovascular medicine. 7th ed. Philadelphia, PA: Elsevier Saunders; 2005. pp 1965-1984.

60. Warnes CA, Williams RG, Bashore TM, et al. ACC/AHA 2008 Guidelines for the Management of Adults With Congenital Heart Disease. Circulation 2008;118:e714-833.

61. Bianca I, Geraci G, Gulizia MM, et al. Documento di consenso ANMCO/SICP/SIGO: Gravidanza e cardiopatie congenite. G Ital Cardiol 2016;17:687.

62. DJ Sexton, SB Calderwood, EL Baron. Antibiotics before procedures (Beyond the Basics). UpToDate 2016 [Epub ahead of print].

63. Rex S, Devroe S. Anesthesia for pregnant women with pulmonary hypertension. Curr Opin Anaesthesiol 2016;29:273.

64. Schinkel AFL. Pregnancy in women with hypertrophic cardiomyopathy. Cardiol Rev 2014;22:217.

65. Pieper PG, Walker F. Pregnancy in women with hypertrophic cardiomyopathy. Neth Heart J 2013;21:14.

66. Regitz-Zagrosek V, Blomstrom Lundqvist C, Borghi C, et al. ESC guidelines on the management of cardiovascular diseases during pregnancy of the European Society of Cardiology. Eur Heart J 2011;32:3147.

67. Gersh BJ, Maron BJ, Bonow RO, et al. 2011 ACCF/AHA guidelines for the diagnosis and treatment of hypertrophic cardiomyopathy. J Thorac Cardiovasc Surg 2011;142:e153.

68. Tromp CHN, Nanne ACM, Pernet PJM, et al. Electrical cardioversion during pregnancy: safe or not? Neth Heart J 2011;19:134.

69. Grewal J, Siu SC, Ross HJ, et al. Pregnancy outcomes in women with dilated cardiomyopathy. J Am Coll Cardiol 2009;55:45.

70. Sliwa K, Hilfiker-Kleiner D, Petrie MC, et al. Current state of knowledge on aetiology, diagnosis, management, and therapy of peripartum cardiomyopathy: a position statement from the Heart Failure Association of the European Society of Cardiology Working Group on Peri- partum Cardiomyopathy. Eur J Heart Fail 2010;12:767.

71. Elkayam U, Akhter MW, Singh H, et al. Pregnancy-associated cardiomyopathy: clinical characteristics and a comparison between early and late presentation. Circulation 2005;111:2050.

72. Mielniczuk LM, Williams K, Davis DR, et al. Frequency of peripartum cardiomyopathy. Am J Cardiol 2006;97:1765.

73. Sliwa K, Fett J, Elkayam U. Peripartum cardiomyopathy. Lancet 2006;368:687.

74. Brar SS, Khan SS, Sandhu GK, et al. Incidence, mortality, and racial differences in peripartum cardiomyopathy. Am J Cardiol 2007;100:302.

75. Witlin AG, Mabie WC, Sibai BM. Peripartum cardiomyopathy: an ominous diagnosis. Am J Obstet Gynecol 1997; 176:182.

76. Kolte D, Khera S, Aronow WS, et al. Temporal trends in incidence and outcomes of peripartum cardiomyopathy in the United States: a nationwide population-based study. J Am Heart Assoc 2014;3:e001056.

77. Gentry MB, Dias JK, Luis A, et al. AfricanAmerican women have a higher risk for developing peripartum cardiomyopathy. J Am Coll Cardiol 2010;55:654.

78. Goland S, Modi K, Hatamizadeh P, et al. Differences in clinical profile of African-American women with peripartum cardiomyopathy in the United States. J Card Fail 2013;19:214.

79. Bello N, Rendon IS, Arany Z. The relationship between pre-eclampsia and peripartum cardiomyopathy: a systematic review and meta-analysis. J Am Coll Cardiol 2013;62:1715.

80. Arany Z, Elkayam U. Peripartum cardiomyopathy. Circulation 2016;133:1397.

81. Fett JD, Christie LG, Carraway RD, et al. Five-year prospective study of the incidence and prognosis of peripartum cardiomyopathy at a single institution. Mayo Clin Proc 2005;80:1602.

82. Isezuo SA, Abubakar SA. Epidemiologic profile of peripartum cardiomyopathy in a tertiary care hospital. Ethn Dis 2007;17:228.

83. Bello N, Arany Z. Molecular mechanisms of peripartum cardiomyopathy: a vascular/hormonal hypothesis. Trends Cardiovasc Med 2015;25:499.

84. Patten IS, Rana S, Shahul S, et al. Cardiac angiogenic imbalance leads to peripartum cardiomyopathy. Nature 2012;485:333.

85. Steegers EA, von Dadelszen P, Duvekot JJ, et al. Preeclampsia. Lancet 2010;376:631.

86. Sliwa K, Mebazaa A. Possible joint pathways of early pre-eclampsia and congenital heart defects via angiogenic imbalance and potential evidence for cardio-placental syndrome. Eur Heart J 2014;35:680.

87. Hilfiker-Kleiner D, Kaminski K, Podewski E, et al. A cathepsin D-cleaved $16 \mathrm{kDa}$ form of prolactin mediates postpartum cardiomyopathy. Cell 2007;128:589.

88. Halkein J, Tabruyn SP, Ricke-Hoch M, et al. MicroRNA$146 \mathrm{a}$ is a therapeutic target and biomarker for peripartum cardiomyopathy. J Clin Invest 2013;123:2143.

89. Podewski EK, Hilfiker-Kleiner D, Hilfiker A, et al. Alterations in Janus kinase (JAK)-signal transducers and activators of transcription (STAT) signaling in patients with end-stage dilated cardiomyopathy. Circulation 2003; 107:798. 
90. Haghikia A, Podewski E, Libhaber E, et al. Phenotyping and outcome on contemporary management in a German cohort of patients with peripartum cardiomyopathy. Basic Res Cardiol 2013;108:366.

91. Sliwa K, Blauwet L, Tibazarwa K, et al. Evaluation of bromocriptine in the treatment of acute severe peripartum cardiomyopathy: a proof of concept pilot study. Circulation 2010;121:1465.

92. Pearson GD, Veille JC, Rahimtoola S, et al. Peripartum cardiomyopathy: National Heart, Lung, and Blood Institute and Office of Rare Diseases (National Institutes of Health) workshop recommendations and review. JAMA 2000;283:1183.

93. Nelson JL. Pregnancy, persistent microchimerism, and autoimmune disease. J Am Med Womens Assoc 1998;53:31.

94. Ansari AA, Fett JD, Carraway RE, et al. Autoimmune mechanisms as the basis for human peripartum cardiomyopathy. Clin Rev Allergy Immunol 2002;23:301.

95. Bültmann BD, Klingel K, Näbauer M, et al. High prevalence of viral genomes and inflammation in peripartum cardiomyopathy. Am J Obstet Gynecol 2005;193:363.

96. Cénac A, Beaufils H, Soumana I, et al. Absence of humoral autoimmunity in peripartum cardiomyopathy. A comparative study in Niger. Int J Cardiol 1990;26:49.

97. Cenac A, Gaultier Y, Devillechabrolle A, et al. Enterovirus infection in peripartum cardiomyopathy. Lancet 1988;2:968.

98. Fett JD. Viral particles in endomyocardial biopsy tissue from peripartum cardiomyopathy patients. Am J Obstet Gynecol 2006;195:330.

99. Demakis JG, Rahimtoola SH, Sutton GC et al. Natural course of peripartum cardiomyopathy. Circulation 1971;44:1053.

100. Elkayam U. Clinical characteristics of peripartum cardiomyopathy in the United States: diagnosis, prognosis, and management. J Am Coll Cardiol 2011;58:659.

101. Chapa JB, Heiberger HB, Weinert L, et al. Prognostic value of echocardiography in peripartum cardiomyopathy. Obstet Gynecol 2005;105:1303.

102. Hibbard JU, Lindheimer M, Lang RM. A modified definition for peripartum cardiomyopathy and prognosis based on echocardiography. Obstet Gynecol 1999;94:311.

103. Diao M, Diop IB, Kane A, et al. Electrocardiographic recording of long duration (Holter) of 24 hours during idiopathic cardiomyopathy of the peripartum [in French]. Arch Mal Coeur Vaiss 2004;97:25.

104. Tokuda M, Stevenson WG, Nagashima K, et al. Electrophysiological mapping and radiofrequency catheter ablation for ventricular tachycardia in a patient with peripartum cardiomyopathy. J Cardiovasc Electrophysiol 2013;24:1299.

105. DeBenedetti Zunino ME, Schuger C, Lahiri M. High rate of ventricular arrhythmias in women with peripartum cardiomyopathy and implanted cardioverter defibrillators. J Am Coll Cardiol 2014;63:A313.

106. Duncker D, Haghikia A, König T, et al. Risk for ventricular fibrillation in peripartum cardiomyopathy with severely reduced left ventricular function-value of the wearable cardioverter/defibrillator. Eur J Heart Fail 2014;16:1331.

107. Saltzberg MT, Szymkiewicz S, Bianco NR. Characteristics and outcomes of peripartum versus nonperipar- tum cardiomyopathy in women using a wearable cardiac defibrillator. J Card Fail 2012;18:21.

108. Gunderson EP, Croen LA, Chiang V, et al. Epidemiology of peripartum cardiomyopathy: incidence, predictors, and outcomes. Obstet Gynecol 2011;118:583.

109. McMurray JJ, Adamopoulos S, Anker SD, et al. ESC Guidelines for the diagnosis and treatment of acute and chronic heart failure 2012: The Task Force for the Diagnosis and Treatment of Acute and Chronic Heart Failure 2012 of the European Society of Cardiology. Developed in collaboration with the Heart Failure Association (HFA) of the ESC. Eur Heart J 2012;33:1787.

110. Yancy CW, Jessup M, Bozkurt B, et al. 2013 ACCF/AHA guideline for the management of heart failure: executive summary: a report of the American College of Cardiology Foundation/American Heart Association Task Force on practice guidelines. Circulation 2013;128:1810.

111. Sims DB, Vink J, Uriel N, et al. A successful pregnancy during mechanical circulatory device support. J Heart Lung Transplant 2011;30:1065.

112. Lee W. Clinical management of gravid women with peripartum cardiomyopathy. Obstet Gynecol Clin North Am 1991;18:257.

113. Alwan S, Polifka JE, Friedman JM. Angiotensin II receptor antagonist treatment during pregnancy. Birth Defects Res A Clin Mol Teratol 2005;73:123.

114. Lavoratti G, Seracini D, Fiorini P, et al. Neonatal anuria by ACE inhibitors during pregnancy. Nephron 1997;76:235.

115. Schubiger G, Flury G, Nussberger J. Enalapril for pregnancy-induced hypertension: acute renal failure in a neonate. Ann Intern Med 1988;108:215.

116. National Institute of Health (NIH). About LactMed. Available from: http://toxnet.nlm.nih.gov/cgibin/sis/htmlgen?LACTMED Accessed: 1 July, 2014.

117. Easterling TR, Carr DB, Brateng D, et al. Treatment of hypertension in pregnancy: effect of atenolol on maternal disease, preterm delivery, and fetal growth. Obstet Gynecol 2001;98:427.

118. Bayliss H, Churchill D, Beevers M, et al. Anti-hypertensive drugs in pregnancy and fetal growth: evidence for "pharmacological programming" in the first trimester? Hypertens Pregnancy 2002;21:161.

119. Lydakis C, Lip GY, Beevers M, et al. Atenolol and fetal growth in pregnancies complicated by hypertension. Am J Hypertens 1999;12:541.

120. Beardmore KS, Morris JM, Gallery ED. Excretion of antihypertensive medication into human breast milk: a systematic review. Hypertens Pregnancy 2002;21:85.

121. Joglar JA, Page RL. Treatment of cardiac arrhythmias during pregnancy: safety considerations. Drug Saf 1999;20:85.

122. Widerhorn J, Rubin JN, Frishman WH, et al. Cardiovascular drugs in pregnancy. Cardiol Clin 1987;5:651.

123. Lees KR, Rubin PC. Treatment of cardiovascular diseases. Br Med J (Clin Res Ed) 1987;294:358.

124. King CR, Mattioli L, Goertz KK, et al. Successful treatment of fetal supraventricular tachycardia with maternal digoxin therapy. Chest 1984;85:573.

125. Vink GJ, Moodley J, Philpott RH. Effect of dihydralazine on the fetus in the treatment of maternal hypertension. Obstet Gynecol 1980;55:519. 
126. Kuzniar J, Skret A, Piela A, et al. Hemodynamic effects of intravenous hydralazine in pregnant women with severe hypertension. Obstet Gynecol 1985;66:453.

127. Hall JB, Schmidt GA. Critical illness. In: Barron WM, Lindheimer MD, eds. Medical disorders during pregnancy. St. Louis, MO: Mosby Inc.; 2000. pp 240.

128. Palmer RF, Lasseter KC. Drug therapy. Sodium nitroprusside. N Engl J Med 1975;292:294.

129. Gherman RB, Goodwin TM, Leung B, et al. Incidence, clinical characteristics, and timing of objectively diagnosed venous thromboembolism during pregnancy. $\mathrm{Ob}$ stet Gynecol 1999;94:730.

130. Refuerzo JS, Hechtman JL, Redman ME, et al. Venous thromboembolism during pregnancy. Clinical suspicion warrants evaluation. J Reprod Med 2003;48:767.

131. Forestier F, Daffos F, Capella-Pavlovsky M. Low molecular weight heparin (PK 10169) does not cross the placenta during the second trimester of pregnancy study by direct fetal blood sampling under ultrasound. Thromb Res 1984;34:557.

132. Forestier F, Daffos F, Rainaut M, et al. Low molecular weight heparin (CY 216) does not cross the placenta during the third trimester of pregnancy. Thromb Haemost 1987;57:234.

133. Weitz JI. Low-molecular-weight heparins. N Engl J Med 1997;337:688.

134. Cosmi B, Hirsh J. Low molecular weight heparins. Curr Opin Cardiol 1994;9:612.

135. Litin SC, Gastineau DA. Current concepts in anticoagulant therapy. Mayo Clin Proc 1995;70:266.

136. Bates SM, Greer IA, Middeldorp S, et al. VTE, thrombophilia, antithrombotic therapy, and pregnancy: antithrombotic therapy and prevention of thrombosis, 9th ed: American College of Chest Physicians EvidenceBased Clinical Practice Guidelines. Chest 2012; 141:e691S.

137. Elsaigh E, Thachil J, Nash MJ, et al. The use of fondaparinux in pregnancy. Br J Haematol 2015;168:762.

138. Knol HM, Schultinge L, Erwich JJ, et al. Fondaparinux as an alternative anticoagulant therapy during pregnancy. J Thromb Haemost 2010;8:1876.

139. Hunt BJ, Doughty HA, Majumdar G, et al. Thromboprophylaxis with low molecular weight heparin (Fragmin) in high risk pregnancies. Thromb Haemost 1997;77:39.

140. Thomson AJ, Walker ID, Greer IA. Low-molecularweight heparin for immediate management of thromboembolic disease in pregnancy. Lancet 1998;352:1904.

141. Jacobsen AF, Qvigstad E, Sandset PM. Low molecular weight heparin (dalteparin) for the treatment of venous thromboembolism in pregnancy. BJOG 2003;110:139.

142. Barbour LA, Oja JL, Schultz LK. A prospective trial that demonstrates that dalteparin requirements increase in pregnancy to maintain therapeutic levels of anticoagulation. Am J Obstet Gynecol 2004;191:1024.

143. Norris LA, Bonnar J, Smith MP, et al. Low molecular weight heparin (tinzaparin) therapy for moderate risk thromboprophylaxis during pregnancy. A pharmacokinetic study. Thromb Haemost 2004;92:791.

144. Bremme K, Lind H, Blombäck M. The effect of prophylactic heparin treatment on enhanced thrombin generation in pregnancy. Obstet Gynecol 1993;81:78.

145. Dahlman TC, Hellgren MS, Blombäck M. Thrombosis prophylaxis in pregnancy with use of subcutaneous heparin adjusted by monitoring heparin concentration in plasma. Am J Obstet Gynecol 1989;161:420.

146. Chunilal SD, Young E, Johnston MA, et al. The APTT response of pregnant plasma to unfractionated heparin. Thromb Haemost 2002;87:92.

147. Roeters van Lennep JE, Meijer E, Klumper FJ, et al. Prophylaxis with low-dose low-molecular-weight heparin during pregnancy and postpartum: is it effective? J Thromb Haemost 2011;9:473.

148. Barbour LA, Smith JM, Marlar RA. Heparin levels to guide thromboembolism prophylaxis during pregnancy. Am J Obstet Gynecol 1995;173:1869.

149. James A, Committee on Practice Bulletins - Obstetrics. Practice bulletin no. 123: thromboembolism in pregnancy. Obstet Gynecol 2011;118:718.

150. Barbour LA. Current concepts of anticoagulant therapy in pregnancy. Obstet Gynecol Clin North Am 1997; 24:499.

151. Bates SM, Ginsberg JS. How we manage venous thromboembolism during pregnancy. Blood 2002; 100:3470.

152. Friedrich E, Hameed AB. Fluctuations in anti-factor Xa levels with therapeutic enoxaparin anticoagulation in pregnancy. J Perinatol 2010;30:253.

153. Brancazio LR, Roperti KA, Stierer R, et al. Pharmacokinetics and pharmacodynamics of subcutaneous heparin during the early third trimester of pregnancy. Am J Obstet Gynecol 1995;173:1240.

154. Pettilä V, Leinonen P, Markkola A, et al. Postpartum bone mineral density in women treated for thromboprophylaxis with unfractionated heparin or LMW heparin. Thromb Haemost 2002;87:182.

155. Backos M, Rai R, Thomas E, et al. Bone density changes in pregnant women treated with heparin: a prospective, longitudinal study. Hum Reprod 1999;14:2876.

156. Cotrufo M, De Feo M, De Santo LS, et al. Risk of warfarin during pregnancy with mechanical valve prostheses. Obstet Gynecol 2002;99:35.

157. Vitale N, De Feo M, De Santo LS, et al. Dose-dependent fetal complications of warfarin in pregnant women with mechanical heart valves. J Am Coll Cardiol 1999;33:1637.

158. Basu S, Aggarwal P, Kakani N, et al. Low-dose maternal warfarin intake resulting in fetal warfarin syndrome: In search for a safe anticoagulant regimen during pregnancy. Birth Defects Res A Clin Mol Teratol 2016;106:142.

159. Stevenson RE, Burton OM, Ferlauto GJ, et al. Hazards of oral anticoagulants during pregnancy. JAMA 1980;243:1549.

160. Chong MK, Harvey D, de Swiet M. Follow-up study of children whose mothers were treated with warfarin during pregnancy. Br J Obstet Gynaecol 1984;91:1070.

161. Whitfield MF. Chondrodysplasia punctata after warfarin in early pregnancy. Case report and summary of the literature. Arch Dis Child 1980;55:139.

162. Zakzouk MS. The congenital warfarin syndrome. J Laryngol Otol 1986;100:215.

163. Beeley L. Adverse effects of drugs in the first trimester of pregnancy. Clin Obstet Gynaecol 1986;13:177.

164. Beeley L. Adverse effects of drugs in later pregnancy. Clin Obstet Gynaecol 1986;13:197.

165. Ginsberg JS, Chan WS, Bates SM, et al. Anticoagula- 
tion of pregnant women with mechanical heart valves. Arch Intern Med 2003;163:694.

166. Ginsberg JS, Hirsh J, Turner DC, et al. Risks to the fetus of anticoagulant therapy during pregnancy. Thromb Haemost 1989;61:197.

167. Salazar E, Izaguirre R, Verdejo J, et al. Failure of adjusted doses of subcutaneous heparin to prevent thromboembolic phenomena in pregnant patients with mechanical cardiac valve prostheses. J Am Coll Cardiol 1996;27:1698.

168. Sbarouni E, Oakley CM. Outcome of pregnancy in women with valve prostheses. Br Heart J 1994;71:196.

169. Howie PW. Anticoagulants in pregnancy. Clin Obstet Gynaecol 1986;13:349.

170. Rutherford SE, Phelan JP. Thromboembolic disease in pregnancy. Clin Perinatol 1986;13:719.
171. Iturbe-Alessio I, Fonseca MC, Mutchinik O, et al. Risks of anticoagulant therapy in pregnant women with artificial heart valves. N Engl J Med 1986;315:1390.

172. Pauli RM, Lian JB, Mosher DF, et al. Association of congenital deficiency of multiple vitamin K-dependent coagulation factors and the phenotype of the warfarin embryopathy: clues to the mechanism of teratogenicity of coumarin derivatives. Am J Hum Genet 1987;41:566.

173. Schaefer C, Hannemann D, Meister R, et al. Vitamin K antagonists and pregnancy outcome. A multi-centre prospective study. Thromb Haemost 2006;95:949.

174. Cohen H, Arachchillage DR, Middeldorp S, et al. Management of direct oral anticoagulants in women of childbearing potential: guidance from the SSC of the ISTH. J Thromb Haemost 2016;14:1673. 